Purdue University

Purdue e-Pubs

CTRC Research Publications

Cooling Technologies Research Center

2015

\title{
Hierarchical Superhydrophobic Copper for Sustained Dropwise Condensation
}

X. Chen

Purdue University

J.A. Weibel

Purdue University, jaweibel@purdue.edu

S V. Garimella

Purdue University, sureshg@purdue.edu

Follow this and additional works at: http://docs.lib.purdue.edu/coolingpubs

Chen, X.; Weibel, J. A.; and Garimella, S V., "Hierarchical Superhydrophobic Copper for Sustained Dropwise Condensation" (2015). CTRC Research Publications. Paper 287.

http://docs.lib.purdue.edu/coolingpubs/287

This document has been made available through Purdue e-Pubs, a service of the Purdue University Libraries. Please contact epubs@purdue.edu for additional information. 


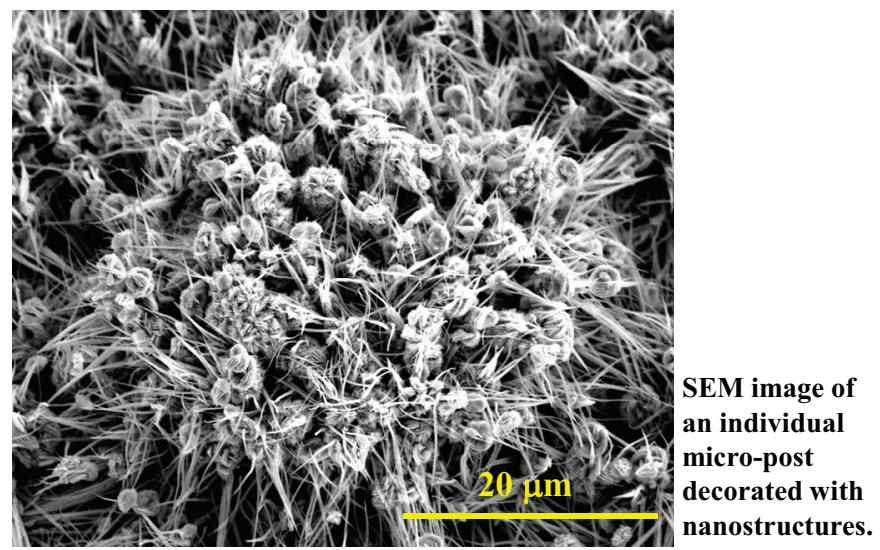

$40 \mathrm{~s}$

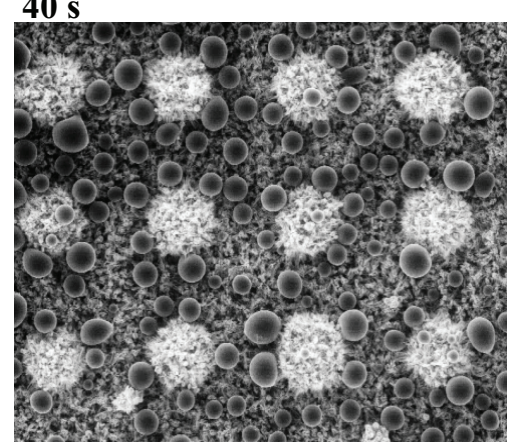

$220 \mathrm{~s}$

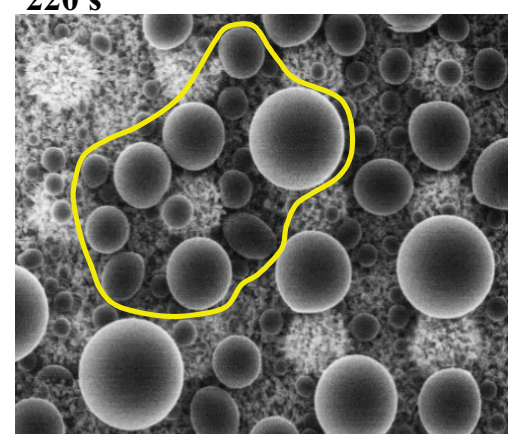

$180 \mathrm{~s}$

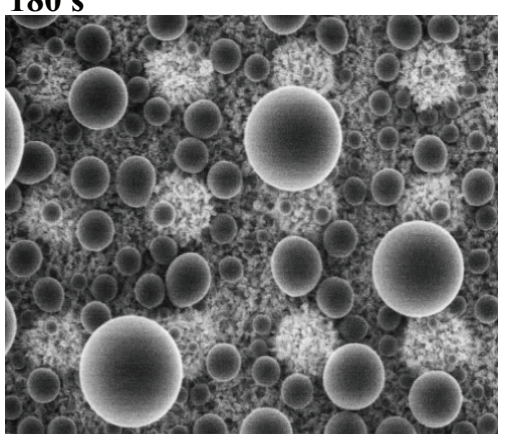

$250 \mathrm{~s}$

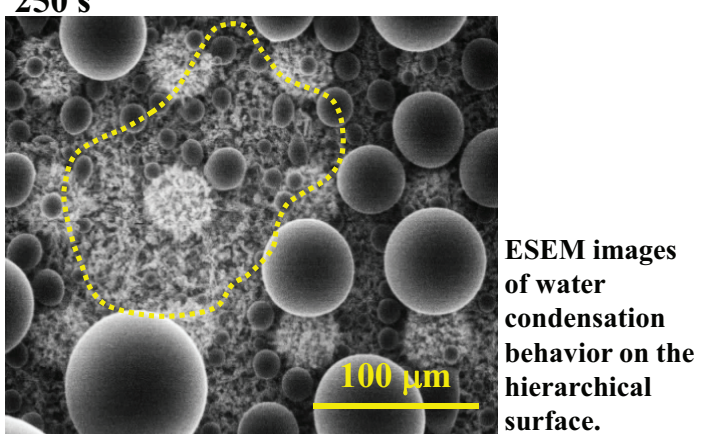

\title{
Hierarchical Superhydrophobic Copper for Sustained Dropwise Condensation
}

\author{
Xuemei Chen, Justin A. Weibel and Suresh V. Garimella \\ School of Mechanical Engineering, Purdue University, West Lafayette, IN 47907-2088 USA
}

\begin{abstract}
Engineering surfaces that sustain continuous dropwise condensation, and are composed of materials commonly employed in heat transfer applications, are of great interest for scaled-up industrial systems. We fabricate hierarchical micro/nano-structured superhydrophobic surfaces on copper substrates. Condensate droplet growth dynamics on the as-fabricated samples were investigated using an environmental scanning electron microscope (ESEM; FEI Quanta 3D, $\sim 6$ torr, $\sim 3{ }^{\circ} \mathrm{C}$ stage). Time-lapse ESEM images show that the condensate droplets preferentially nucleate at the bases of the hill-shaped microstructures (40 s). The droplets at the microstructure bases coalesce; merged droplets rise and appear to be suspended atop adjacent microstructures (180-220 s). These droplets, when triggered by coalescence, can gain sufficient kinetic energy by a reduction in droplet surface area/energy to spontaneously depart from the substrate. This droplet motion sweeps additional droplets in the trajectory and exposes fresh space for formation of new droplets (220-250 s). These droplet growth and departure dynamics are facilitated by the combination of microscale and nanoscale roughness features on the surface, and the behavior provides important insight into surface design requirements for sustaining dropwise condensation in thermal management applications.
\end{abstract}

